\title{
Characterization of duplex coating system (HVOF + PVD) on light alloy substrates
}

\author{
J.A. Picas ${ }^{\mathrm{a}, *}$, S. Menargues ${ }^{\mathrm{a}}$, E. Martin ${ }^{\mathrm{a}}$, C. Colominas ${ }^{\mathrm{b}}$, M.T. Baile ${ }^{\mathrm{a}}$. \\ ${ }^{a}$ Light Alloys and Surface Treatments Design Centre. Department of Materials Science and \\ Metallurgy. Universitat Politècnica de Catalunya. Rambla Exposició 24, 08800 Vilanova i la \\ Geltrú; Spain. \\ bGrup d'Enginyeria de Materials. Institut Químic de Sarrià. Universitat Ramon Llull. Via Augusta \\ 390, 08017 Barcelona; Spain \\ *Corresponding author: Tel: +34938967213, Fax: +34938967201, E-mail address: \\ josep.picas@upc.edu.
}

\begin{abstract}
Light metals such as aluminium or magnesium alloys play an important role in many different industrial applications. However, aluminium and especially magnesium alloys show relatively poor resistance to sliding wear, low hardness and load bearing capacity, so that surface performance improvement is recommended, often by PVD processes.

This study evaluates the tribological improvement achieved by applying a duplex coating on AW7022 aluminium alloy or AZ91 magnesium alloy substrates, consisting of a thick coating interlayer, deposited by High Velocity Oxygen Fuel (HVOF), followed by a PVD (TiN, TiAlN) or PE-CVD (DLC) hard top layers.

The deposition of thermal sprayed HVOF coatings, as primary layer, leads to improvement of the load bearing capacity of the substrates and allows reducing the tendency of hard thin top layer to cracking and delamination when is directly deposited on a softer substrate. The number of laps to failure, in the pin-on-disc wear tests, of TiN and TiAlN PVD coatings deposited on the harder interlayer HVOF coating were significantly higher (3000 and 1400 laps, respectively) than the values measured for these coatings deposited directly on the aluminium substrate (140 and 120 laps, respectively).
\end{abstract}


The best combination of properties was obtained with the DLC top layer deposited on the thermally sprayed coatings, with a significant reduction of friction coefficient (less than 0.10), which remains almost unchanged even after 40000 laps in the pin-on-disc wear tests.

Keywords: HVOF Thermal spray; Physical Vapour Deposition (PVD); Plasma-Enhanced Chemical Vapour Deposition (PE-CVD); Light alloys; Tribology; Hardness.

\section{Introduction}

Many factors can influence vehicle energy consumption and emissions, among which the weight of vehicle is a key one. For these reasons, there is a growing effort to substitute conventional steel and cast irons with light metals and alloys. Aluminium and magnesium based materials, are the materials of choice for transport applications, such as aerospace, automotive and light rail, because of their lowdensity and high strength-to-weight ratio. However, the relatively poor surface properties of these materials represent a serious barrier to their wider application. For example, magnesium alloys have an extremely poor corrosion resistance in most environments, and both materials are characterised, especially in sliding situations, by poor tribological properties. Therefore, it is necessary to improve their surface properties using suitable functional surface coatings capable of providing adequate protection against wear and corrosion. A wide range of surface modification methods are available for aluminium and magnesium products, such as conversion coatings (with chromates or phosphates), anodizing, electrolytic and electroless nickel plating, laser alloying, laser melt injection, thermal spray etc. [1-8]. Furthermore, the progress in the area of manufacturing and extending the life expectancy of the aluminium and magnesium components, is taking place mostly owing to the more and more common employment of thin coatings deposition made from hard, wear resistant ceramic materials. Currently, a PVD (Physical Vapour Deposition) method plays an important role for improving properties in those applications which involve high contact stresses and severe sliding wear [9-14]. PVD thin hard coatings can be used to improve tribological performances of aluminium and magnesium, even if endurance and reliability problems do still exist when high contact stress with plastic deformation of the substrate or contact fatigue occur. In this case differences in both coating and substrate hardness and stiffness do not provide a good distribution of contact stresses and either plastic deformation of the substrate or high tensile contact stress within the ceramic coating are likely to occur, providing problems of loss of adherence and detachment of the top hard layer, giving rise to a collapse of the coatings, the so-called “egg scale effect” [15-18]. Moreover, the presence of localised cracks under contact or tribological loads could generate electro-chemical corrosion between substrate and the PVD coating [19-20]. 
A solution can be presented by duplex systems, obtained by the sequential use of two (or more) coating technologies to have properties which are not obtainable through a single process. An optimized duplex coating, consisting of a thick interlayer and a thin ceramic top layer can be proposed. Thermal spraying appears a particularly suitable technique for the deposition of the thick interlayer, because it is highly flexible and it finds numerous industrial applications on a wide range of simple or complex shaped components. Specifically, HVOF-sprayed cermet coatings seem highly promising as an interlayer, on account of their high hardness, good toughness and high modulus [15, 16, 21, 22]. Furthermore, the tribological and mechanical properties of the thermally sprayed coating would likely be improved by the PVD top coating [15, 16, 23, 24]. In this sense, the thermal spray interlayer coating would provide a good support to the top ceramic coating, allowing a better distribution of contact stresses and preventing its delamination.

The main goal of this work was to investigate the potential of a duplex hard coating system, consisting of a HVOF thermally sprayed thick interlayer and a PVD or PE-CVD thin top layer to improve the surface performance of aluminium alloy and magnesium alloy substrates.

\section{Experimental details}

\subsection{Materials and Processes}

Duplex coating systems were obtained, on top of AW-7022 aluminium alloy and AZ91 magnesium alloy substrates, by the sequential deposition of $86 \mathrm{WC}-14 \mathrm{CoCr}$ or $75 \mathrm{Cr}_{3} \mathrm{C}_{2}-25 \mathrm{NiCr}$ thick coatings, by a High Velocity Oxygen Fuel technique, followed of TiN or TiAlN top layer, by Physical Vapour Deposition (PVD), or CrC/DLC hard thin top layer, by Plasma-Enhanced Chemical Vapour Deposition (PE-CVD).

A Sulzer Metco WokaJet-400 HVOF thermal spray facility was used for the thermal spraying of powders, using kerosene as liquid fuel. The spray parameters used for the 86WC-10Co4Cr powder were: spray distance $260 \mathrm{~mm}$; fuel flow rate $18.2 \mathrm{l} \cdot \mathrm{h}^{-1}$; oxygen flow rate $944 \mathrm{slpm}$ (standard litre per minute), and for the $75 \mathrm{Cr}_{3} \mathrm{C}_{2}-25 \mathrm{NiCr}$ powder were: spray distance $360 \mathrm{~mm}$; fuel flow rate $25.3 \mathrm{l} \cdot \mathrm{h}^{-1}$; oxygen flow rate $900 \mathrm{slpm}$. All coatings were deposited onto aluminium and magnesium substrates, which were grit-blasted before spraying. The average thicknesses of HVOF coatings were $100 \mu \mathrm{m}$ with a surface roughness $(\mathrm{Ra})$ around $3.5 \mu \mathrm{m}$. In order to prepare the HVOF coating surface for the subsequent deposition of the PVD or PE-CVD coatings, an accurate polishing sequence was carried 
out to obtain a surface roughness level $(\mathrm{Ra})$ near $0.02 \mu \mathrm{m}$, which will allow a better adhesion of the hard thin top layers.

Finally the samples were degreased and cleaned by ion sputtering inside the film deposition chamber, using a high energy ion bombardment $\left(\mathrm{Ar}^{+}\right)$. The TiN and TiAlN thin layers, as a top coat, were deposited on the HVOF coatings by reactive pulsed DC magnetron sputtering using an industrial scale CemeCon CC 800/9ML reactor, with four unbalanced magnetrons. Furthermore, to conduct a comparative study, the TiN and TiAlN thin layers were also deposited directly on the AW-7022 substrate. For TiN, four Ti targets were used, whereas one Ti target and $3 \mathrm{Ti}-\mathrm{Al}$ targets (500x88x10 $\mathrm{mm}$ ) were used for TiAlN. DLC was deposited by Plasma-Enhanced Chemical Vapour Deposition (PE-CVD), by reacting acetylene simultaneously to graphite sputtering. Previously to the deposition of DLC coating, a PVD-sputtered chromium interlayer was applied to increase adhesion on the HVOF coating. This Cr layer was later transformed into chromium carbide during the process of DLC deposition. Coating deposition cycle was 180 minutes for TiN and TiAlN layers and 240 minutes for DLC layer. These PVD and PE-CVD layers were precisely deposited using proprietary process parameters (Flubetech, SL; Spain) in order to obtain a dense, non-columnar coating structure having the highest possible adhesion level.

\subsection{Characterization}

The coating microstructure was examined by means of a scanning electron microscope (SEM, Jeol JSM-5600). Backscattered electron images were obtained, and EDS analysis was conducted. Samples for SEM observation of the coatings were sectioned from a transverse section and prepared by standard metallographic techniques. The porosity and thickness of the coatings were evaluated by image analysis technique (Leica Qwin) using a Leica optical microscope. The roughness (Ra) was measured by a Taylor-Hobson roughness tester.

The coating hardness was determined with an ultramicrohardness testing system (Fischerscope HCU) capable of measuring continuously force and displacement, using a Vickers diamond indentor. While testing force $\mathrm{F}$ is being increased, indentation depth is being measured continuously both for loading and unloading sequences, getting the corresponding indentation depth-force curve that allows to evaluate the following properties: Martens hardness HM (hardness under maximum applied load), plastic hardness $H$ (hardness after removal the applied load), elastic recovery We (percentage of deformation recovery evaluated from unloading curve and calculated after removal of the applied 
load) and effective Young's modulus $E^{*}=E /\left(1-v^{2}\right)$, where $E$ and $v$ are the Young's modulus and the Poisson ratio respectively. The dynamic hardness measurements were carried out with applied load from $0.4 \mathrm{mN}$ to $100 \mathrm{mN}$ as a final load (20 steps, every $1 \mathrm{~s}$ ). Each average value has been calculated from 15 different measurements, discarding the anomalous values as consequence of the coating defects.

Tribological evaluation of duplex coating systems was performed, under dry conditions, using a pin on disc tribometer (CSEM Instruments), according to ASTM wear testing standard G-99. The tests were carried out by sliding a $6 \mathrm{~mm}$ diameter WC-6Co sintered pin against the coated substrates at a constant linear speed of $0.05 \mathrm{~m} \cdot \mathrm{s}^{-1}$ with an applied load of $5 \mathrm{~N}$. All the tests were conducted at $25{ }^{\circ} \mathrm{C}$ with a relative humidity of approximately $50 \%$. Three different tests were conducted for each test condition and material. The friction coefficient was plotted as a function of the number of laps in the test.

Scratch tests were performed for adhesion evaluation of the coatings and provide some quantitative information on the interface between PVD or PE-CVD and HVOF coatings and compare the adhesion/cohesion failure of different coatings. The scratch tests were carried out using a CSEM Revetest device, by moving the diamond indenter along the examined specimen surface with gradually increasing load. The device registered the friction force, friction coefficient, indenter penetration depth and acoustic emission along the scratch track. The scratch length was $5 \mathrm{~mm}$ and the applied load was varied between 5 and $100 \mathrm{~N}$ with a loading rate of $37.5 \mathrm{~N} \cdot \mathrm{min}^{-1}$. Three scratch tests were performed in each test case to obtain the mean values. After the tests the coatings were evaluated using optical microscopy, evaluating at which critical force severe cracking and detaching started to occur.

\section{Results and discussion}

\subsection{Microstructural Characterization of the Coatings}

Fig. 1 shows a SEM image of the polished cross-section of the PVD TiAlN and PE-CVD CrC/DLC top layers on HVOF WC-CoCr interlayer and Fig. 2 shows a SEM image of the polished cross-section of the PVD TiAlN and TiN top layers on HVOF $\mathrm{Cr}_{3} \mathrm{C}_{2}-\mathrm{NiCr}$ interlayer. The compositional distributions of HVOF coatings show an essentially two phase structure of carbides in a metallic matrix. In both coatings the carbide grains retained a blocky shape with slightly rounded edges, reflecting some degree of dissolution during spray deposition, even though the size distribution of the 
carbide phase was wide, suggesting no preferential dissolution of the smaller particles. Very dense HVOF coatings can be seen with a porosity level lower than $1 \%$. The top coatings show a singlephase microstructure and the interfaces between top thin layers and HVOF thermally sprayed interlayers present quite good adherence and homogeneity. The average thicknesses of the deposited coatings are shown in Table 1.

Fig. 3 shows the multilayer PE-CVD and HVOF coatings deposited onto aluminium and magnesium substrates. In both cases, the metallic substrates were significantly deformed by the impacting particles due to high kinetic energy involved in the HVOF thermal spray process. The high deformation level of the aluminium and magnesium substrates suggests a good mechanical anchoring between the HVOF coating and both the light substrates. Furthermore, the high thickness of the HVOF interlayer limits the effect of the substrate (aluminium or magnesium) on the surface properties of the hard thin top layers.

\subsection{Mechanical and tribological evaluation of duplex coating system (HVOF + PVD)}

The microhardness values, measured in the top coating surface and in the cross-section of the HVOF thermally sprayed interlayer, are shown in Table 2. PVD TiN and TiAlN top layers show the expected high levels of hardness, even though evidenced the effect of the hardness of the HVOF thermally sprayed interlayer in the measured hardness values. Hardness measurements were performed with $100 \mathrm{mN}$ of applied load that involved an indentation depth around $0.4 \mu \mathrm{m}$ so that the measured hardness return a composite hardness, bearing the influence of both the top coating and the underlying

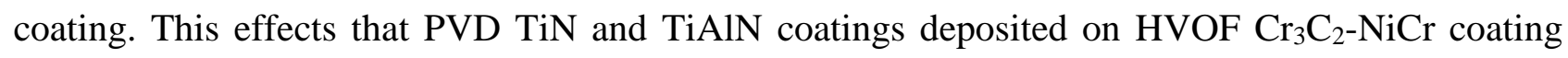
present a slightly lower hardness (higher penetration depth in the hardness test) compared to those deposited on the harder HVOF WC-CoCr coating (Fig. 4). Moreover, the hardness results of these coatings, deposited directly on the aluminium substrate, clearly show the effect of the soft substrate on the mechanical properties of the thin top layer, resulting in a significant decrease in the measured surface hardness. In a different way, the lower thickness of the DLC coating (1.2 $\mu \mathrm{m})$ effects that the measured values are strongly influenced by the properties of the PVD CrC and HVOF underlayers. The penetration depth is higher than $10 \%$ of the thickness of the DLC top layer, and consequently the hardness values obtained for the DLC top layer are significantly less than those expected for this kind of coating. 
On the other hand, several studies have underlined that hardness is not necessarily the prime requirement for wear resistance and load bearing capacity. In particular, elastic strain to failure, which is related to $\mathrm{H} / \mathrm{E}$ ratio of the surface layer, can be a more suitable parameter for predicting wear resistance and describes elastic failure related with the cracking resistance (toughness indicative), and in case of components whose function specifically requires resistance to local contact load, the most effective index seems to be $\left(\mathrm{H}^{3} / \mathrm{E}^{2}\right)$ ratio, which can be related to the contact yield pressure (i.e. resistance to plastic deformation) [25-26]. In this sense, the maximum values of $\mathrm{H} / \mathrm{E}$ and $\mathrm{H}^{3} / \mathrm{E}^{2}$ and ratios (see Table 2) correspond with the TiAlN-HVOF system that could be expected to be harder and tougher than the TiN-HVOF system.

To determine the tribological properties of the evaluated coatings, a wear test under dry sliding friction conditions was carried out by the pin-on-disk method. This pin-on-disk test design (sliding wear) also provides relevant information about adhesion and fatigue of the surface layers. Table 2 presents the friction coefficient results for each coating. Comparing the friction coefficient results, it has been found that the best wear resistance is characteristic for materials coated with DLC coating. According to the applied load of $5 \mathrm{~N}$, the average friction coefficients for the DLC coatings is in the range of 0.08 to 0.11 , which is several times lower compared to the friction coefficient values of TiN and TiAlN coatings ( 0.28 and 0.26 respectively). Moreover, the DLC coating shows a much lower steady-state frictional coefficient that remains almost unchanged even after 40000 laps (Fig. 5a). This behaviour is characteristic for DLC coatings which contrary to CVD diamond coatings are constituted by wide amorphous zones, that means the C-atoms are in no order at all, which are probably formed by a friction-assisted phase transformation of the surface layer of the DLC matrix and acts as a lubricant at the surface [27]. Accordingly, the high hardness of DLC together with this transfer layer is responsible for the low friction coefficient of the DLC film in comparison the other investigated coatings. In contrast, the TiN and TiAIN coatings were always delaminated before the end of the tests run (Fig. 5b). In this case, the main wear mechanism is the fatigue fracture in the contact region. The repeated friction under elastic or elastoplastic contact causes the accumulation of local plastic strain around some stress concentration points, and causes initiation and growth of microcracks leading to chipping on the coated surface. This effect is more significant in the TiN and TiAlN coatings deposited directly on the A7022 aluminium substrate, in which the lower hardness of the substrate causes a higher elastoplastic deformation of these coatings during the sliding tests, accelerating the fatigue fracture mechanism and resulting in a premature coating detachment. Table 2 shows that the number of laps to coating failure of both coatings deposited on the aluminium substrate are 
significantly lower than the values measured for the coatings deposited on the harder underlayer HVOF coating.

Moreover, table 2 also shows the friction coefficient for pure HVOF coatings (without top thin coats). The friction coefficients of 86WC-14CoCr and 75Cr3C2-25NiCr HVOF coatings are very similar to those presented by the TiN and TiAlN PVD coatings, although they are significantly higher compared to DLC coating. In these HVOF coatings the wear mechanism is very different from that seen in PVD coatings and mainly consists in the progressive removal of metal matrix and exposure of carbide grains followed by the pull out of individual carbide particles or small agglomerates of carbides and matrix, resulting in a third-body abrasive wear mechanism.

The adhesion of the top coatings to the HVOF interlayers was evaluated using scratch test method. The failure of the coating is characterized by sudden change in friction coefficient or contact acoustic emission with the normal force during the scratch test. Adhesion strength of the coating or thin film is characterized by the corresponding load at which friction coefficient and acoustic emission exhibit a sudden change. At this turning point, the normal force is regarded as the critical normal force which, if sufficiently large, induces adhesive failure. Fig. 6 shows data from scratch-adhesion tests, at a sliding speed of $37.5 \mathrm{~N} . \mathrm{min}^{-1}$ over a distance of $5 \mathrm{~mm}$, of PVD TiAlN coating on HVOF WC-CoCr interlayer. At the point of failure, at load slightly higher than $20 \mathrm{~N}$, both friction coefficient and acoustic emission abruptly increased and the penetration depth decreased. In this study, the critical normal force was used to assess the adhesion strength of top ceramic coatings on HVOF interlayers. The critical force obtained by the scratch test for each studied multilayer coatings are shown in Table 2. The highest critical force, and therefore the best adhesion of the top coating to the HVOF interlayer, was obtained for the TiN/WC-CoCr system, which is not the best result obtained in the wear tests, carried out at $5 \mathrm{~N}$ of applied load, in which other characteristics such as the friction coefficient were involved. These results suggest that in sliding contact condition a low friction coefficient can prevent or delay the detachment of the coating, although the adherence between the top coating and the interlayer/substrate could be smaller.

Furthermore, Fig. 7 shows the optical observation of the scratched TiN coating. The images show that the scratch channels were composed of two stages before and after the diamond indenter reached the TiN coating/HVOF coating interface. The first stage, at low normal force, involved the film deformation which starts to cause some adhesive failures of TiN coating (Fig. 7a). In the second stage, 
the total layer cracking was observed into the scratch channel owing to the deformations of TiN layer and HVOF interlayer (Fig. 7b).

\section{Conclusions}

The concept of a duplex coating system, comprising a hard thin top layer and a thick HVOF interlayer, can be effectively used to improve the friction and wear properties of aluminium and magnesium substrates, under dry sliding conditions. Without protective coatings, light metal substrates show poor tribological behaviour. Nevertheless, the deposition of different thin hard layers directly on the light metal substrates did not significantly improve its surface properties, because of the poor adhesion of these coatings and due to the low load bearing capacity of the light alloy substrates.

In this research, WC-CoCr and $\mathrm{Cr}_{3} \mathrm{C}_{2}$-NiCr coatings have been successfully applied on $\mathrm{Mg}$ and $\mathrm{Al}$ alloys substrates, by the High Velocity Oxygen Fuel technique, with high bond strengths. The deposition of these HVOF coatings, as primary layer, leads to improvement of the load bearing capacity of the substrates and allows reducing the tendency of hard thin top layer to cracking and delamination when it is directly deposited on a softer substrate. In this sense, the number of laps to failure, in the pin-on-disc wear tests, of TiN and TiAlN PVD coatings deposited directly on the aluminium substrate were significantly lower (140 and 120 laps respectively) than the values measured for these coatings deposited on the harder underlayer HVOF coating (higher than 3000 and 1400 laps respectively). The results of this work have also shown that the use of thick HVOF interlayers implies that the characteristics of the substrate (aluminium or magnesium) do not significantly affect the properties of the thin top ceramic layer.

PVD TiN and TiAlN coatings showed higher hardness than HVOF WC-CoCr and $\mathrm{Cr}_{3} \mathrm{C}_{2}-\mathrm{NiCr}$ coatings, and PE-CVD CrC/DLC multilayer thin film effectively improved the tribological properties of thermally sprayed coatings, with a significant reduction of friction coefficient (less than 0.1 ), which remains almost unchanged even after 40000 laps in the pin-on-disc wear tests. This lower friction coefficient assured a higher integrity of the DLC top coating under dry sliding contact.

The duplex coating system (PVD or PE-CVD + HVOF) represents an effective solution in improving the adhesion and tribological properties of the hard thin layers on ductile light-alloy components. The use of combined layers will open new fields for the use of light metal alloys in many tribological applications. 


\section{References}

[1] J.E. Gray, B. Luan, Protective coatings on magnesium and its alloys - a critical review. J. Alloy. Compd. (2002) 88-113.

[2] R.O. Hussein, D.O. Northwood, X. Nie, The effect of processing parameters and substrate composition on the corrosion resistance of plasma electrolytic oxidation (PEO) coated magnesium alloys, Surf. Coatings Technol. 237 (2013) 357-368.

[3] M. Parco, L. Zhao, J. Zwick, K. Bobzin, E. Lugscheider, Investigation of HVOF spraying on magnesium alloys, Surf. Coatings Technol. 201 (2006) 3269-3274.

[4] H. Pokhmurska, B. Wielage, T. Lampke, T. Grund, M. Student, N. Chervinska, Post-treatment of thermal spray coatings on magnesium, Surf. Coatings Technol. 202 (2008) 4515-4524.

[5] S. G. Xin, J. Le, L.X. Song, Composition and Hardness of the Coating Containing Zirconia Produced by Micro-Arc Oxidation on Aluminium Alloy, Key Eng. Mater. 512-515 (2012) 10821088.

[6] S.A. Kumar, S. Raman, R. Gnanamoorthy, Performance of alumina coatings prepared by hard anodizing, micro arc oxidation and detonation spray processes on Al-Mg-Si alloy under fretting wear loading, Proceedings of the Institution of Mechanical Engineers, Part J (Journal of Engineering Tribology), 228 (2014) 454-62.

[7] J. A. Picas, A. Forn, R. Rilla, E. Martín, HVOF thermal sprayed coatings on aluminium alloys and aluminium matrix composites, Surf. Coatings Technol. 200 (2005) 1178-1181.

[8] H. Hornberger, S. Virtanen, A.R. Boccaccini, Biomedical coatings on magnesium alloys-A review, Acta Biomater. 8 (2012) 2442-2455.

[9] R. Gadow, D. Scherer, Composite coatings with dry lubrication ability on light metal substrates. Surf. Coatings Technol. 151-152 (2002) 471-477.

[10] T. Tański, Characteristics of Hard Coatings on AZ61 Magnesium Alloys, J. Mech. Eng. 59 (2013) 165-174.

[11] G. Wu, W. Dai, H. Zheng, A. Wang, Improving wear resistance and corrosion resistance of AZ31 magnesium alloy by DLC/AlN/Al coating, Surf. Coatings Technol. 205 (2010) 2067-2073.

[12] H. Altun, S. Sen, The effect of PVD coatings on the wear behaviour of magnesium alloys, Mater. Charact. 58 (2007) 917-921.

[13] T. Tański, K. Labisz, Electron microscope investigation of PVD coated aluminium alloy surface layer, Solid State Phenom.186 (2012) 192-197.

[14] N. Yamauchi, K. Demizu, N. Ueda, N.K. Cuong, T. Sone, Y. Hirose, Friction and wear of DLC films on magnesium alloy, Surf. Coatings Technol. 193 (2005) 277- 282. 
[15] E. Bemporad, M. Sebastiani, D. De Felicis, F. Carassiti, R. Valle, F. Casadei, Production and characterization of duplex coatings (HVOF and PVD) on Ti-6Al-4V substrate, Thin Solid Films 515 (2006) 186-194.

[16] G. Bolelli, L. Lusvarghi, M. Montecchi, F. Pighetti Mantini, F. Pitacco, H. Volz, M. Barletta, HVOF-sprayed WC-Co as hard interlayer for DLC films, Surf. Coatings Technol. 203 (2008) 699703.

[17] K. Holmberg, H. Ronkainen, A. Laukkanen, K. Wallin, Friction and wear of coated surfacesscales, modelling and simulation of tribomechanisms, Surf. Coatings Technol. 202 (2007) 1034-1049. [18] O. Wänstrand, M. Larsson, A. Kassman-Rudolphi, An experimental method for evaluation of the load-carrying capacity of coated aluminium: the influence of coating stiffness, hardness and thickness, Surf. Coatings Technol. 127 (2000) 107-113.

[19] J. Komotori, B.J. Lee, H. Dong, P.A. Dearnley, Corrosion response of engineered titanium alloys damaged by prior abrasion, Wear 251 (2001) 1239-49.

[20] C. Liu, Q. Bi, A. Matthews, Tribological and electrochemical performance of PVD TiN coatings on the femoral head of Ti-6Al-4V artificial hip joints, Surf. Coatings Technol. 163-164 (2003) 597604.

[21] X. Liu, P. K. Chu, C. Ding, Surface modification of titanium, titanium alloys, and related materials for biomedical applications, Mater. Sci. Eng. R 47 (2004) 49-121.

[22] J. Vetter, G. Barbezat, J. Crummenauer, J. Avissar, Surface treatment selections for automotive applications, Surf. Coatings Technol. 200 (2005) 1962-1968.

[23] E. Bemporad, M. Sebastiani, M.H. Staia, E. Puchi Cabrera, Tribological studies on PVD/HVOF duplex coatings on Ti6Al4V substrate, Surf. Coatings Technol. 203 (2008) 566-571.

[24] E. Bemporad, M. Sebastiani, F. Casadei, F. Carassiti, Modelling, production and characterisation of duplex coatings (HVOF and PVD) on Ti-6Al-4V substrate for specific mechanical applications, Surf. Coatings Technol. 201 (2007) 7652-7662.

[25] A. Leyland, A. Matthews, On the significance of the H/E ratio in wear control: a nanocomposite coating approach to optimised tribological behaviour, Wear 246 (2000) 1-11.

[26] J. Musil, F. Kunc, H. Zeman, H. Poláková, Relationships between hardness, Young’s modulus and elastic recovery in hard nanocomposite coatings, Surf. Coatings Technol. 154 (2002) 304-313.

[27] K. Lukaszkowicz, L.A. Dobrzański, Structure and mechanical properties of gradient coatings deposited by PVD technology onto the X40CrMoV5-1 steel substrate, J. Mater. Sci. 43 (2008) 34003407. 